\title{
EVALUASI KETINGGIAN BANGUNAN DALAM RANGKA UPAYA MENJAGA ZONA KKOP BANDARA JUANDA (Studi Kasus : Masjid Ar-Ridlo Sedati Sidoarjo)
}

\section{EVALUTION THE HEIGHT BUILDING FOR SAVING SAFETY ZONE FLIGHT OPERATION OF JUANDA AIRPORT (A case study: Ar-Ridlo Mosque Sedati Sidoarjo)}

\author{
Hepi Hapsari Handayani ${ }^{1}$, Ridha Rahmawan ${ }^{1}$ \\ ${ }^{1}$ Institusi Teknologi Sepuluh Nopember \\ Email: hepihapsari@gmail.com
}

\begin{abstract}
Abstrak
Seiring dengan perkembangan pertumbuhan pembangunan dari yang awalnya secara horizontal menuju ke pembangunan secara vertikal, mengakibatkan munculnya banyak gedung - gedung baru yang memiliki ketinggian yang beragam. Hal ini bisa menjadi masalah jika keberadaannya berada pada area sekitar Bandara. Karena gedung tersebut dapat menjadi halangan pesawat terbang dalam melakukan pendaratan maupun lepas landas. Oleh karena itu dibutuhkan batas-batas ketinggian yang diperbolehkan dalam melakukan pembangunan secara vertikal

Di Indonesia batas-batas tersebut dikenal dengan Kawasan Keselamatan Operasi Penerbangan (KKOP) yang ada pada setiap bandara di indonesia Dalam penelitian ini Masjid Ar-Ridlo dijadikan sebagai studi kasus penelitian. Penelitian ini akan menghasilkan data ketinggian dari masjid tersebut dengan mempertimbangkan factor perbedaan permukaan tanah.
\end{abstract}

Kata Kunci: Halangan, Ketinggian, KKOP

\begin{abstract}
Along with the development growth from the horizontally development to the vertically development, It can make many new building with diverse heigh. The height building can make some problem if that building exist near from the airport. Because it can be an obstacle of airplane for landing to the airport and take off from the airport. Because of that required the limits of the permissible height in doing development vertically. In Indonesia the regulation of that permission is known as Safety Flight Operation Zone. That regulation exist in every airport in Indonesia.

In this study, Masjid Ar-Ridlo be used as a case study research. This study will generate data on the height of the mosque at ground level difference factors.
\end{abstract}

Keywords : Obstacle, Altitude, KKOP

\section{PENDAHULUAN}

\section{Latar Belakang}

Izin Mendirikan Bangunan atau biasa dikenal dengan IMB adalah perizinan yang diberikan oleh Kepala Daerah kepada pemilik bangunan untuk membangun baru, mengubah, memperluas, mengurangi, dan/atau merawat bangunan sesuai dengan persyaratan administratif dan persyaratan teknis yang berlaku. IMB merupakan salah satu produk hukum untuk mewujudkan tatanan tertentu sehingga tercipta ketertiban, keamanan, keselamatan, kenyamanan, sekaligus kepastian hukum. Kewajiban setiap orang atau badan yang akan mendirikan bangunan memiliki Izin Mendirikan Bangunan terdapat (Pasal 5 ayat 1 Perda 7 tahun 2009).

IMB akan melegalkan suatu bangunan yang direncanakan sesuai dengan Tata Ruang yang telah ditentukan. Selain itu, adanya IMB menunjukkan bahwa rencana konstruksi bangunan tersebut juga dapat dipertanggungjawabkan dengan maksud untuk kepentingan bersama. Dalam hal ini ketinggian 
bangunan akan menjadi fokus dalam penelitian ini.

Pada KKOP Bandara Juanda terdapat masalah pada tahun 2010 tentang ketinggian bangunan City of Tomorrow (Cito) surabaya yang dikeluhkan oleh para pilot. Bangunan ini berada pada jarak 8 kilometer dari bandara dengan ketinggian maksimal 115 meter (Asdhiana, 2010) Pada penelitian ini akan dilakukan pengukuran terhadap objek bangunan masjid Ar-Ridlo dengan mempertimbangkan aspek perbedann permukaan tanah yang selanjutnya dilakukan analisa ketinggian masjid dengan batas - batas ketinggian zona ancangan pendaratan dan lepas landas Bandara Juanda.

\section{METODOLOGI PENELITIAN}

\section{Data Dan Peralatan}

- Data

Data yang digunakan dalam penelitian ini adalah:

1. Ketinggian Masjid Ar-Ridlo dari pengukuran menggunakan Total Staion

2. Koordinat dari pengukuran menggunakan GPS Geodetik

3. Keputusan Kementrian Perhubungan no KM 5 tahun 2004

\section{- Peralatan}

Peralatan yang digunakan dalam penelitian ini adalah:

1. Total Station Reflector Less

2. GPS Geodetik

\section{Metode Penelitian}

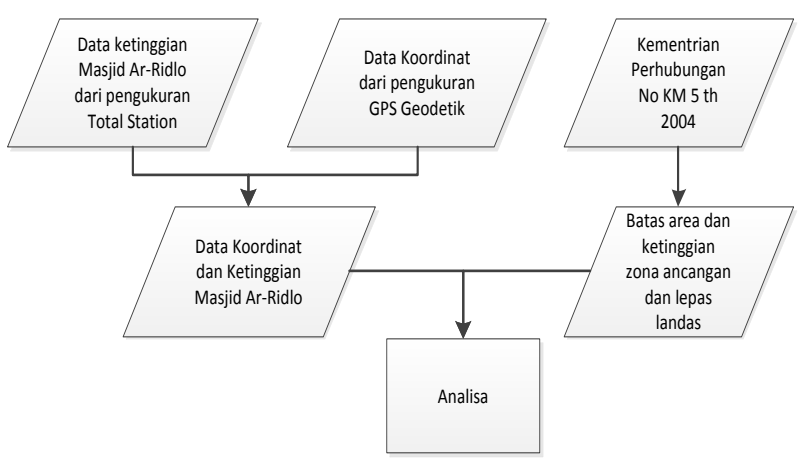

Gambar 1. Flowchart Penelitian

\section{- Pembagian Zona Ancangan dan Lepas} Landas Bandara Juanda

Untuk membuat zona ancangan dan lepas landas bandara juanda diketahui dari surat keputusan kementerian perhubungan no KM 5 tahun 2004.

Dalam keputusan tersebut telah dijelaskan batas - batas zona dan ketinggian yang diperbolehkan untuk mendirikan bangunan atau halangan lain pada setiap ujung landasan seprti pada tabel berikut:

Tabel 1. Pembagian zona kawasan pendekatan dan lepas landas landasan 10

\begin{tabular}{llll}
\hline Zona & $\begin{array}{l}\text { Slope } \\
(\%)\end{array}$ & $\begin{array}{l}\text { Tinggi maksimal } \\
(\mathrm{m})\end{array}$ & $\begin{array}{l}\text { Jarak } \\
(\mathrm{m})\end{array}$ \\
\hline Bagian 1 & 2 & 45 & 2230 \\
Bagian 2 & 0 & 45 & 1700 \\
Bagian 3 & 5 & 103 & 1180 \\
Bagian 4 tengah & 2 & & 2300 \\
Bagian 4 tepi 1 & 5 & & 436 \\
Bagian 4 tepi 2 & 2.5 & & 968 \\
Bagian 4 tepi 3 & 0 & & 896 \\
Bagian 5 & 0 & 150 & 7520 \\
\hline
\end{tabular}

Tabel 2. Pembagian zona kawasan pendekatan dan lepas landas landasan 28

\begin{tabular}{llll}
\hline zona & $\begin{array}{l}\text { Slope } \\
(\%)\end{array}$ & $\begin{array}{l}\text { Tinggi maksimal } \\
(\mathbf{m})\end{array}$ & $\begin{array}{l}\text { Jarak } \\
(\mathbf{m})\end{array}$ \\
\hline Bagian 1 & 2 & 45 & 2250 \\
Bagian 2 & 0 & 45 & 1750 \\
Bagian 3 & 5 & 103 & 1167 \\
Bagian 4 tengah & 2 & & 2333 \\
Bagian 4 tepi 1 & 5 & & 433 \\
Bagian 4 tepi 2 & 2.5 & & 1000 \\
Bagian 4 tepi 3 & 0 & & 900 \\
Bagian 5 & 0 & 150 & 7500 \\
\hline
\end{tabular}

\section{- Pengukuran Koordinat Elevasi Tanah}

Pengukuran ini bertujuan untuk mendapatkan koordinat acuan dan mengetahui berapa kemiringan tanah antara bandara dengan objek yang akan dilakukan pengukuran ketinggian.

Pengukuran ini menggunakan alat GPS Geodetik yang dipasang pada BM Otoritas Bandara Juanda sebagai base dan acuan ketinggian landasan dan titik yang berdakatan dengan masjid Ar-Ridlo sebagai rover untuk mendapatkan koordinat acuan 
dan ketinggian permukaan tanah. Data yang didapatkan beeracuan pada elipsoid WGS 84.

Pengukuran yang digunakan dalam penelitian ini adalah pengukuran dengan metode statik (static positioning), yaitu penentuan posisi dari titik - titik yang statik (diam). Penentuan posisi tersebut dapat dilakukan secara absolut maupun differensial, dengan menggunakan data pseudorange dan/atau fase.

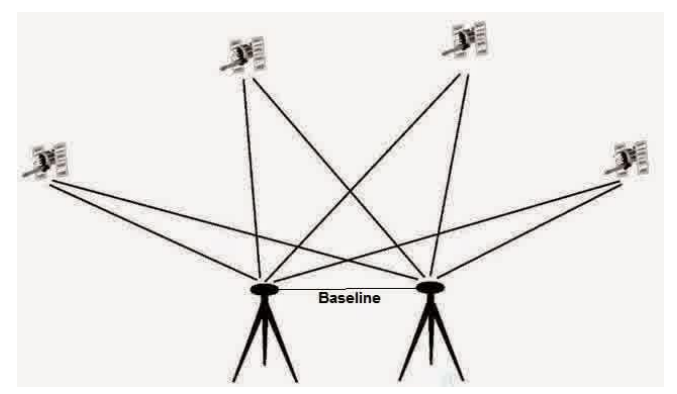

Gambar 2. Ilustrasi Pengukuran posisi titik dengan metode survei GPS (Abidin, 2007)

\section{- Pengukuran Ketinggian Bangunan}

Ketinggian bangunan didapatkan dengan melakukan pengukuran lapangan menggunakan alat total Station.

Cara dasar penggunaan total station adalah dengan mendirikan alat tersebut di titik yang sudah diketahui atau ditentukan (lokal) koordinatnya, lalu bidikkan ke arah prisma atau benda secara langsung. maka alat tersebut akan dapat menghitung secara otomatis jarak, sudut, hingga koordinat titik tersebut tergantung dari mode yang digunakan pada alat. Ilustrasi pengukuran menggunakan TS dapat diihat pada gambar.[2]

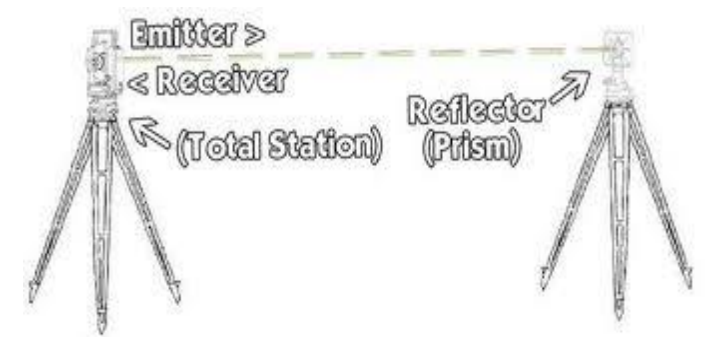

Gambar 3. Pengukuran Total Station (Amanullah, 2013)

Pada Penelitian ini pengukuran dilakukan dengan cara tanpa menggunakan prisma sebagai penerima laser total station, melainkan langsung mengenai objek yang diukur dalam hal ini adalah pucuk kubah masjid Ar-Ridlo.

Data yang dihasilkan oleh alat tersebut selanjutnya diikatkan pada $B M$ rover yang telah dibuat menggunakan alat GPS Geodetik untuk mendapatkan koordinat dan ketinggian dari bangunan.

Data pengukuran tersebut terlebih dahulu dilakukan perhitungan standar deviasi dengan menggunakan rumus berikut.

$$
\sigma=\sqrt{\frac{\sum(\mathrm{X}-\overline{\mathrm{X}})^{2}}{\mathrm{~N}-1}}
$$

Data hasil perhitungan standar deviasi selanjutnya dilakukan perhitungan tingkat kepercayaan 95\% untuk validasi data dengan rumus berikut.

$$
\text { (E95\%) }=\overline{\mathrm{X}} \pm \mathrm{Z} * \frac{\sigma}{\sqrt{\mathrm{N}}}
$$

Data yang masuk dalam tingkat kepercayaan $95 \%$ selanjutnya dapat digunakan.

\section{HASIL DAN PEMBAHASAN}

\section{Pembuatan Zona Ancangan dan Lepas Landas Bandara Juanda}

Setelah mengetahui pembagian dari setiap area dari zona ancangan pendaratan dan lepas landas, selanjutnya dilakukan penggambaran pada software Autocad.

Penggambaran dilakukan secara tampak atas dan tampak samping. Hal ini bertujuan untuk melihat posisi dan ketinggian dan bangunan tersebut.

Berikut adalah gambar dari zona ancangan pendaratan dan lepas landas pada software Autocad. 


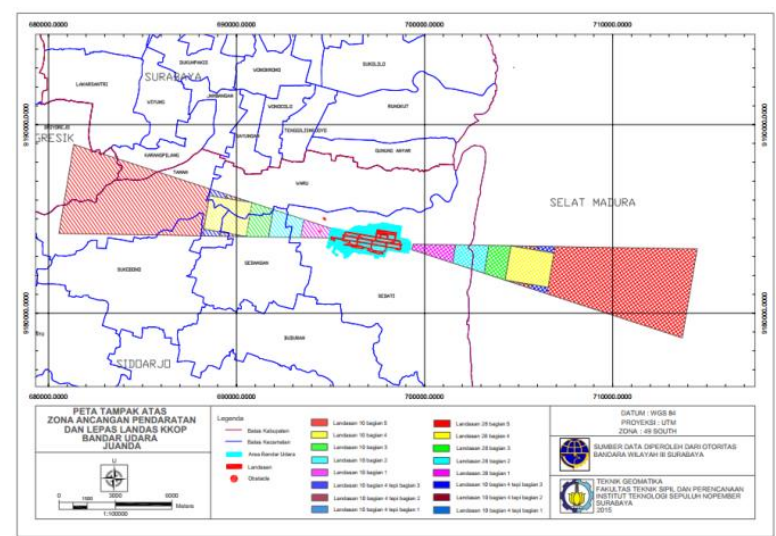

Gambar 4. Gambar Peta Zona Ancangan Pendaratan dan Lepas Landas Tampak Atas

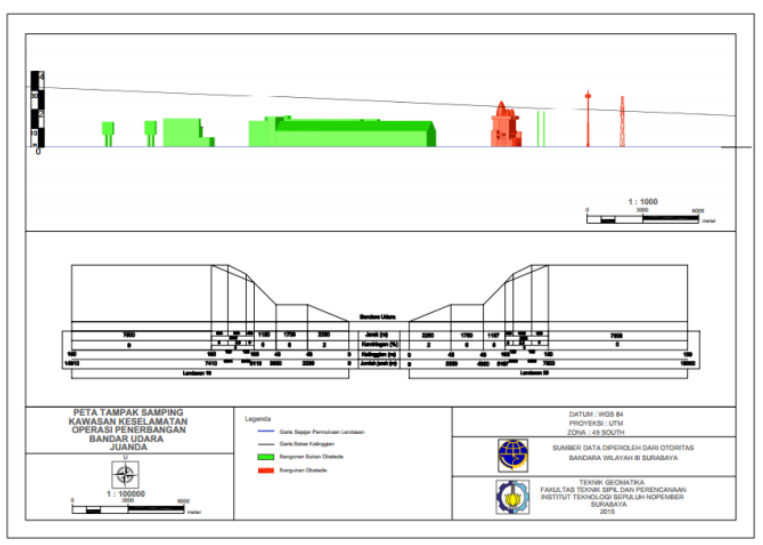

Gambar 5. Gambar Peta Zona Ancangan Pendaratan dan Lepas Landas Tampak Samping

Pengukuran Koordinat Elevasi Tanah

Hasil dari pengukuran GPS Geodetik mendapatkan koordinat dan elevasi tanah sebagai berikut.

Tabel 3. Data Koordinat hasil pengukuran GPS Geodetik

\begin{tabular}{cccc}
\hline Position & Name & Northing (m) & Easting (m) \\
\hline Base & Base1 & 9184459,447 & 697460,273 \\
& & & \\
Posisi 1 & RVR1 & 9184992,528 & 694677,261 \\
& RVR2 & 9184997,008 & 694663,617 \\
Posisi 2 & RVR3 & 9184238,759 & 694592,398 \\
& RVR4 & 9184247,678 & 694593,577 \\
& & & \\
Posisi 3 & RVR5 & 9184734,501 & 694256,407 \\
& RVR6 & 9184739,733 & 694259,958 \\
\hline
\end{tabular}

Tabel 4. Data Elevasi hasil pengukuran GPS Geodetik

\begin{tabular}{ccc}
\hline Position & Name & Elevation $(\mathbf{m})$ \\
\hline Base & Base1 & 35,273 \\
Posisi 1 & RVR1 & 34,918 \\
& RVR2 & 35,036 \\
Posisi 2 & RVR3 & 35,321 \\
& RVR4 & 35,221 \\
& & \\
Posisi 3 & RVR5 & 35,131 \\
& RVR6 & 35,175 \\
\hline
\end{tabular}

Dari tabel 3 dan 4, dapat dicari selisih ketinggian dari permukaan tanah. terlihat perbedaan permukaan tanah yang bereferensi terhadap landasan bandara juanda.

\section{Pengukuran Ketinggian Bangunan}

Hasil dari pengukuran total station mendapatkan data koordinat dan ketinggian bangunan yang telah diikatkan dengan data GPS Geodetik, sehingga koordinat yag dihasilkan telah bereferensi pada pengukuran GPS dan ketinggian yang dihasilkan telah bereferensi ketinggian BM Otoritas bandara juanda.

Data pengukuran tersebut terlebih dahulu dilakukan perhitungan standar deviasi dan tingkat kepercayaan $95 \%$ untuk dilakukan validasi data.

Data hasil perhitungan kepercayaan 95\% selanjutnya dapat digunakan untuk analisa.

Tabel 5. Data Koordinat hasil pengukuran Total Station

\begin{tabular}{cccc}
\hline Nomor & $\mathbf{X}(\mathbf{m})$ & $\mathbf{Y}(\mathbf{m})$ & Jenis \\
\hline 1 & 694620.938 & 9185016.63 & Baliho \\
2 & 694614.775 & 9185026.05 & Baliho2 \\
3 & 694662.031 & 9185023.03 & Tiang \\
4 & 694704.682 & 9184964.89 & $\begin{array}{c}\text { Tiang2 } \\
\text { Masjid Ar- } \\
\text { Ridlo } \\
5\end{array}$ \\
& 694565.066 & 9184268.87 & Hotel \\
6 & 694338.939 & 9184784.35 & Halogen \\
7 & 694261.261 & 9184680.13 & MM Resto \\
8 & 694212.144 & 9184739.94 & Gedung \\
9 & 694146.243 & 9184595.24 & Baliho3
\end{tabular}




\begin{tabular}{cccc}
10 & 694195.093 & 9184684.56 & Baliho4 \\
11 & 694237.472 & 9184854.68 & Pendopo \\
\hline 12 & 694243.480 & 9184892.38 & Pendopo2 \\
\hline
\end{tabular}

Tabel 6. Data Ketinggian hasil pengukuran Total Station

\begin{tabular}{cc}
\hline Tinggi $(\mathbf{m})$ & Jenis \\
\hline 18.853 & Baliho \\
18.959 & Baliho2 \\
26.627 & Tiang \\
30.757 & Tiang2 \\
24.531 & Masjid Ar-Ridlo \\
16.816 & Hotel Halogen \\
16.221 & MM Resto \\
15.215 & Gedung \\
13.111 & Baliho3 \\
13.729 & Baliho4 \\
\hline 12.241 & Pendopo \\
11.780 & Pendopo2 \\
\hline
\end{tabular}

Dari tabel diatas diketahui ketinggian masjid ArRidlo adalah $24.531 \mathrm{~m}$ dengan posisi $694565.066,9184268.87$ yang berarti terletak pada area 1 dari zona ancangan pendaratan dan lepas landas landasan 10.

Posisi masjid berada pada $1124.984 \mathrm{~m}$ dari batas landasan, yang berarti memiliki batas ketinggian sebesar $22.702 \mathrm{~m}$.

Dengan demikian masjid Ar-Ridlo telah menjadi halangan (obstacle) dari Bandara Juanda

\section{PENUTUP}

Pada Penelitian ini dapat disimpulkan bahwa Masjid Ar-Ridlo yang berada pada posisi 694565.066,9184268.87 dengan ketinggian $24.531 \mathrm{~m}$ adalah obstacle dari Bandara Juanda. Sehingga perlu dilakukan penurunan sebesar $1.829 \mathrm{~m}$ pada bangunan sebagai tindak lanjut untuk memberikan keamanan pesawat dalam melakukan pendaratan maupun lepas landas dari bandara juanda.

\section{DAFTAR PUSTAKA}

Abidin, H,Z. 2007.Penentuan Posisi dengan GPS dan Aplikasinya. Jakarta: Pradnya Paramita

Amanullah, F. 2013. Analisa Perbandingan Volume cut and fill Menggunakan Total Station dan GPS
CORS (Continously Operating Reference Station) Metode RTK NTRIP. Institut Teknologi Sepuluh Nopember. Surabaya

Asdhiana, I, M. Pengelola Bandara Juanda Cuma Pasrah.http://regional.kompas.com/read/201 0/06/19/22403540/Pengelola.Bandara.Juanda .Cuma.Pasrah-5 (23 Juni 2015)

Basuki, S. 2006.Ilmu Ukur Tanah.Gadjah Mada University Press. Yogyakarta

Kementerian Perhubungan. 2004. Keputusan Mentri Perhubungan nomor KM 5 Tahun 2004 tentang Kawasan Keselamatan Operasi Penerbangan di Sekitar Bandar Udara Juanda dan sekitarnya. Menteri Perhubungan. Jakarta

Undang Undang Republik Indonesia nomor 1 Tahun 2009. Penerbangan.

Pemerintah Kota Surabaya. 2009. Peraturan Daerah kota Surabaya Nomor 7 tahun 2009 tentang Bangunan. Walikota Surabaya. Surabaya 